\title{
No effects of bosentan on microvasculature in patients with limited cutaneous systemic sclerosis
}

\author{
Martha E. Hettema • Dan Zhang • Ymkje Stienstra • \\ Andries J. Smit • Hendrika Bootsma • \\ Cees G. M. Kallenberg
}

Received: 7 October 2008 /Revised: 11 December 2008 / Accepted: 5 March 2009/Published online: 7 April 2009

C) The Author(s) 2009. This article is published with open access at Springerlink.com

\begin{abstract}
The endothelium-derived vasoconstrictor molecule endothelin-1 (ET-1) has been suggested to play a role in the pathogenesis of Raynaud's phenomenon (RP) and systemic sclerosis (SSc). We studied the effect of bosentan on microvascular structure and function in patients with RP secondary to limited cutaneous SSc in a mechanistic pilot study. In this single center, open study, 15 patients with limited cutaneous SSc were treated with bosentan for 16 weeks with a follow-up period of 4 weeks. Changes in microvascular structure and function were studied with assessment of vasodilatory microvascular responses using laser Doppler fluxmetry combined with iontophoresis, capillary permeability using fluorescence videomicroscopy, nailfold capillary microscopy, and serological markers of endothelial activation. No significant changes were seen in vasodilator responses to acetylcholine and sodium nitroprusside following bosentan treatment. No effect was noted on capillary permeability during treatment. The number of nailfold capillaries remained unchanged. The endothelial activation marker vascular cell adhesion molecule did not
\end{abstract}

M. E. Hettema $(\bowtie) \cdot$ D. Zhang $\cdot$ H. Bootsma $\cdot$

C. G. M. Kallenberg

Department of Rheumatology and Clinical Immunology,

University Medical Center Groningen, University of Groningen, P.O. Box 30001, 9700 RB Groningen, The Netherlands

e-mail: M.Hettema@ziekenhuis-mst.nl

Y. Stienstra

Department of Internal Medicine,

University Medical Center Groningen, University of Groningen, Groningen, The Netherlands

\author{
A. J. Smit \\ Department of Vascular Medicine, \\ University Medical Center Groningen, University of Groningen, \\ Groningen, The Netherlands
}

change during treatment, but levels of thrombomodulin significantly decreased after 12 weeks of treatment. Bosentan did not induce significant changes in vasodilator responses, capillary permeability, and capillary density during treatment, so no evidence was obtained for structural improvement of microvascular structure and function in this short-time mechanistic pilot study in patients with lcSSc.

Keywords Bosentan - Endothelial cell dysfunction . Raynaud's phenomenon $\cdot$ Systemic sclerosis

\section{Introduction}

Raynaud's phenomenon (RP) is present in more than $95 \%$ of patients with systemic sclerosis (SSc) and is often the first manifestation of the disease [1, 2]. Endothelial cell dysfunction, associated with microvascular and macrovascular abnormalities, is a hallmark of SSc. Signs of endothelial dysfunction include increased capillary permeability [3, 4], dysregulation of vascular tone [5-7], and elevated markers of endothelial cell injury, such as von Willebrand Factor (vWF), trombomodulin (TM), and soluble vascular adhesion cell molecule-1(s-VCAM-1) [8-13].

Endothelin-1 (ET-1), a potent vasoconstrictor, has been suggested to play a role in the pathogenesis of RP and SSc. Increased levels of ET-1 have been found in patients with primary and secondary RP [14-19]. Recently, treatment with bosentan, an ET-1 receptor antagonist, has been shown to be effective in preventing new digital ulcers in patients with SSc. Although this effect was seen both in patients with limited and diffuse cutaneous SS, only the reduction in patients with diffuse cutanous SSc was statistically significant. No improvement was seen in symptoms of RP [20]. We found an encouraging improvement in frequency, 
duration, and severity of RP attacks in 15 patients with SSc who used bosentan during a period of 16 weeks. The Raynaud's Condition Score improved from $4.8 \pm 2.6$ at baseline to $2.7 \pm 2.1$ after 16 weeks of treatment $(p=$ 0.003 ), and also a significant reduction in total number and duration of RP attacks was found. However, our study was not placebo-controlled and no objective improvement in blood flow was seen [21].

We hypothesized that the beneficial effects of bosentan in the prevention of digital ulcers and maybe also, as suggested in our previous study, in SSc-associated RP could be explained by its effects on microvascular structure and function in this condition. To test this hypothesis, we assessed acetylcholine-dependent vasodilatory responses using laser Doppler fluxmetry with iontophoresis, capillary permeability using fluorescence videomicroscopy, and nailfold capillaroscopy and markers of endothelial activation, at baseline, during treatment, and after discontinuation of bosentan in patients with SSc and severe RP.

\section{Materials and methods}

Patients

Patients from the outpatient clinic with a diagnosis of Raynaud's phenomenon secondary to systemic sclerosis were eligible for the study. Patients had to be at least 18 years old, have a diagnosis of RP as assessed by history and photoelectric plethysmography during cooling and rewarming [22], and digital pitting scars and/or ulceration. Patients had to fulfill the American College of Rheumatology criteria for systemic sclerosis [23]. Patients were subclassified in subsets as defined by LeRoy et al. [1]. Inclusion criteria otherwise included no prior use of bosentan and the use of a reliable method of contraception during the study. Patients were not eligible in case of digital ulcers due to other conditions than SSc, prostanoid therapy during the last month, sympathectomy of the upper limb performed within 12 months before study entry, current smoking or smoking within 4 weeks before study entry, and any other severe concurrent illness. All patients had to provide written informed consent. Medication used for the treatment of SSc was allowed and had to remain unchanged from 3 months prior to study entry until the end of the study. Vasodilators, such as calcium channel antagonists and ketanserin, and other oral medications for the treatment of RP, such as angiotensin converting enzyme inhibitors, were allowed and were continued at the same dosage throughout the study. A total of 15 patients, all with limited cutaneous SSc, were recruited. All patients were enrolled during the months of December and January, except for one, who enrolled in the study at the beginning of February. No differences in outdoor temperature were seen until week 12. Baseline characteristics of the patients are shown in Table 1. To compare the results regarding endothelial markers and the results of laser Doppler flowmetry and iontophoresis, 15 historical age- and sex-matched healthy subjects were included as controls.

Study design and drug administration

The study was an open study. Ethical approval for the study was obtained from the Medical Ethical Committee of the University Medical Center Groningen, The Netherlands. There was a 2-4 weeks pretreatment period, followed by 16 weeks of treatment and a 4 weeks post-treatment followup. Patients entering the study started with bosentan orally, $62.5 \mathrm{mg}$ bid for 4 weeks, followed by the target dose of $125 \mathrm{mg}$ bid for 12 weeks. Clinical outcome measurements were recorded at baseline, week 8 , week 16 , and week 20 , except for the endothelial markers. The laboratory assessments were performed every 4 weeks.

Table 1 Baseline characteristics

\begin{tabular}{|c|c|}
\hline Characteristic & $N=15$ \\
\hline Sex & No. $(\%)$ \\
\hline Male & $1(7)$ \\
\hline Female & $14(93)$ \\
\hline Age & Year \\
\hline Median (range) & $52(34-70)$ \\
\hline Type of systemic sclerosis & No. $(\%)$ \\
\hline Limited cutaneous & $15(100)$ \\
\hline Duration of systemic sclerosis & Year \\
\hline Median (range) & $4(1-10)$ \\
\hline Duration of Raynaud's phenomenon & Year \\
\hline Median (range) & $10(2-26)$ \\
\hline Immunosuppressive agents & No. $(\%)$ \\
\hline \multicolumn{2}{|l|}{ Current use } \\
\hline Methotrexate & $4(27)$ \\
\hline \multicolumn{2}{|l|}{ Former use } \\
\hline Methotrexate & $1(7)$ \\
\hline Cyclophosphamide & $1(7)$ \\
\hline Azathioprine & $1(7)$ \\
\hline Never & $8(53)$ \\
\hline Concomitant treatment & No. $(\%)$ \\
\hline Calcium-channel blockers & $10(67)$ \\
\hline Angiotensin converting enzyme inhibitors & $6(40)$ \\
\hline Ketanserin & $5(33)$ \\
\hline Statins & $2(13)$ \\
\hline Aspirin & $6(40)$ \\
\hline Coumarin & $2(13)$ \\
\hline
\end{tabular}


Clinical outcome measurements

\section{Laser Doppler fluxmetry in combination with iontophoresis}

Microvascular endothelium-dependent and endotheliumindependent vasodilation was evaluated with laser Doppler fluxmetry (LDF) combined with iontophoresis of acetylcholine (ACh) and sodium nitroprusside (SNP) as described previously [24]. Briefly, after a baseline recording of $5 \mathrm{~min}$ at rest (baseline flux), iontophoresis was started by setting time and current strength based on previously documented and accepted protocols of multiple fixed doses [25-27]. $\mathrm{ACh}$ response was measured at the dorsal side on the middle phalanx of the third finger of the dominant hand and SNP on the same site on the nondominant hand. ACh $(1 \%$, Miochol, IOLAB, Bourneville Pharma, The Hague, The Netherlands) was delivered in seven doses of $0.1 \mathrm{~mA}$ using an anodal current for $20 \mathrm{~s}$, with a 60 -s interval between each dose to achieve a plateau phase, whereas SNP $(0.1 \%$, dissolved in $\mathrm{NaCl} 0.9 \%$ ) was delivered in nine doses of $0.2 \mathrm{~mA}$ using a cathodal current for $20 \mathrm{~s}$ with a $60-\mathrm{s}$ interval between each dose. The measurements were performed sequentially. The order of $\mathrm{ACh}$ and SNP delivery was random. The mean flux of the first $5 \mathrm{~min}$ excluding moving artifacts made up the baseline flux. The plateau flux was defined as the mean flux during the last 2 min of the plateau phase. Absolute increase was defined as the difference between plateau flux and baseline flux. Relative increase (vasodilation) was defined as the ratio of absolute increase and baseline flux. Previous studies found a day-to-day variation coefficient for ACh-mediated vasodilation of 10-16\% and for SNP-mediated vasodilation of $8-16 \%$, in healthy subjects on two occasions $[26,28,29]$. We found comparable variation coefficients, i.e. $16 \%$ for ACh-mediated vasodilation and $18 \%$ for SNP-mediated vasodilation, as determined in ten individuals on two separate days.

\section{Capillary permeability using fluorescein diffusion with 'large field' fluorescence videodensitometry}

Large-window sodium fluorescein $(\mathrm{NaF})$ videodensitometry was used to measure skin capillary permeability according to the method described by Jager et al. [30]. The system consists of an epiillumination microscope (Olympus BHMJ, Tokyo, Japan) to which a $75 \mathrm{~W}$ Xenon lamp (Osram XBO, Berlin, Germany) is mounted. Emitted light is filtered using a fluorescence filter set (Olympus BH2-UDMB, excitation $380-490 \mathrm{~nm}$, barrier $515 \mathrm{~nm}$, Tokyo, Japan). A $2 \times 3-\mathrm{mm}$ section of the skin of the medial malleolus of the ankle was visualized (magnification $\mathrm{x} 100)$. Immersion oil (Leitz, din 58884, Wetzlar, Germany) was applied to the skin to increase transparency. A bolus of
$\mathrm{NaF}$ solution $(0.3 \mathrm{ml}$ of a $15 \% \mathrm{NaF}$ solution per liter of estimated blood volume) was injected intravenously. The epiillumination microscope visualizes the rapid capillary appearance and the subsequent interstitial leakage of $\mathrm{NaF}$. Images were recorded by a video camera (Grundig FA-85, Fürth/Bay, Germany), in which an automatic gain function was removed, and a S-VHS video recorder. Images were digitized from tape recording (Data Translation 2862 framegrabber with Iris software) after first appearance of the dye every second for $20 \mathrm{~min}$. The fluorescence light intensity (FLI) of each image was computed and expressed in arbitrary units. One baseline image was digitized to obtain background FLI, which was subtracted from subsequent intensities. Individual maximum intensity $\left(I_{\max }\right)$ was set at $100 \%$. All other intensities were expressed as percentages of $I_{\max }$. The average relative intensity over the first $7 \min \left(I_{\mathrm{av}}(7)\right)$ after appearance of the dye was used as a parameter of $\mathrm{NaF}$ transcapillary and interstitial diffusion. This value showed a day-to-day variability, expressed as coefficient of variation, of $10 \%$ [30]. Dye arrival time (DAT) was defined as the interval from injection of the dye until appearance in skin capillaries [31].

\section{Nailfold capillary microscopy}

An epiillumination microscope (Olympus BHMJ, Tokyo, Japan) was used for nailfold capillary microscopy. The finger of the subject to be examined was placed under the microscope. All studies were performed in a temperature controlled room $\left(24^{\circ} \mathrm{C}\right)$. The nailfolds of the middle finger and ringfinger of both hands were examined by widefield microscopy after acclimatization to room temperature for 15 min. Immersion oil (Leitz, din 58884, Wetzlar, Germany) was applied to the finger to increase transparency of the skin. Images were recorded by a video camera (Grundig FA-85, Fürth/Bay, Germany) and a S-VHS video recorder. The tapes were evaluated separately by two observers by using a previously described protocol [32]. Numbers of capillary loops in a defined area of $3 \mathrm{~mm}$ in the middle of the distal row of nailfold capillaries were counted. The mean score of two observers was given. Patterns of the visible capillary loops were not scored.

\section{Blood analysis}

Serum and plasma samples for measuring endothelial markers were stored at $-20{ }^{\circ} \mathrm{C}$ until analysis. Serum levels of vascular cell adhesion molecule 1 (s-VCAM-1, R\&D Systems, Abingdon, UK) and thrombomodulin (TM, Diaclone, Besançon, France) were measured according to the manufacturer's instruction. Von Willebrand factor (vWF) was determined using in-house enzyme-linked immunosorbent assays as described before [33]. 
Statistical analysis

Values are expressed as mean $\pm \mathrm{SD}$. In the analysis of the laser Doppler fluxmetry with iontophoresis the Wilcoxon signed-rank test was used. $\mathrm{NaF}$ leakage curves were compared by paired $t$-tests using the area under the curve (AUC) of the first $500 \mathrm{~s}$. Analysis of the other NaF leakage parameters, number of nailfold capillaries, and endothelial markers before, during, and after treatment was performed with a paired samples $t$-test. Differences between patients and age- and sex-matched healthy controls for LDF with iontophoresis and endothelial markers were assessed by Student's $t$-test or Mann-Whitney $U$ as appropriate. A twosided $p$-value of $<0.05$ was considered significant.

\section{Results}

Laser Doppler fluxmetry in combination with iontophoresis

Compared to age- and sex-matched controls a significantly decreased ACh-mediated (endothelial-dependent) vasodilation was found in patients before treatment with bosentan $(187 \pm 154 \%$ (mean \pm SD) in patients vs $595 \pm 448 \%$ in controls, $p=0.001)$. SNP-mediated (endothelial-independent) vasodilation was comparable between $\mathrm{SSc}$ patients and controls $(402 \pm 413 \%$ vs $637 \pm 759 \%, p=0.138)$.
An increased baseline and plateau flux was seen after 16 weeks of treatment. This improvement was not reflected in or accompanied by a significant increase in AChmediated vasodilation nor in SNP-mediated vasodilation (Table 2, Fig. 1). No significant difference was found in vasodilation during treatment or after discontinuation of bosentan.

\section{Fluorescence videomicroscopy}

The averaged sodium fluorescein leakage curves, obtained before treatment, and at week 8 , week 16 , and week 20 , are shown in Fig. 2. The curves for the relative fluorescence light intensity were comparable before, during, and after discontinuation of bosentan, although after 8 weeks, when comparing the area under the curve, a trend towards increased $\mathrm{NaF}$ leakage $(p=0.051)$ was observed (Table 3 ). At the same time, a shorter, though not significantly, dye arrival time was found $(p=0.196)$, suggesting an improvement in skin blood flow. The results of the other capillary sodium fluorescein leakage parameters are also summarized in Table 3. The average relative fluorescence light intensity $\left(\mathrm{I}_{\mathrm{av}}(7)\right)$ did not significantly change during the study. The DAT showed a trend to be longer after 16 weeks of treatment $(p=0.075)$ and was significantly longer at week 20 $(p=0.044)$ when compared to baseline. No difference was seen in DAT between week 16 and 20. The prolonged DAT

Table 2 Results of laser Doppler flowmetry and iontophoresis

\begin{tabular}{|c|c|c|c|c|}
\hline & Before treatment $(N=15)$ & Week $8(N=14)$ & Week $16(N=12)$ & Week $20(N=9)$ \\
\hline \multicolumn{5}{|l|}{ ACh-mediated vasodilation } \\
\hline Baseline flux (PU) & $32.1 \pm 30.5$ & $47.0 \pm 37.4$ & $56.4 \pm 45.4^{*}$ & $33.3 \pm 38.3$ \\
\hline Change from pretreatment values & & $16.9 \pm 42.5$ & $24.7 \pm 32.5$ & $-2.42 \pm 51.7$ \\
\hline Plateau flux (PU) & $71.0 \pm 46.2$ & $96.8 \pm 61.8$ & $123.2 \pm 93.8^{*}$ & $69.2 \pm 60.5$ \\
\hline Change from pretreatment values & & $31.9 \pm 76.4$ & $55.8 \pm 88.1$ & $7.3 \pm 67.7$ \\
\hline Absolute increase (PU) & $39.0 \pm 35.1$ & $49.2 \pm 38.8$ & $66.8 \pm 65.3$ & $35.9 \pm 33.3$ \\
\hline Change from pretreatment values & & $15.0 \pm 52.2$ & $31.1 \pm 60.3$ & $9.8 \pm 44.8$ \\
\hline ACh-mediated vasodilation (\%) & $187.3 \pm 154.4$ & $142.2 \pm 202.6$ & $116.2 \pm 84.2$ & $142.8 \pm 124.7$ \\
\hline Change from pretreatment values & & $-47.0 \pm 264.3$ & $-81.0 \pm 127.2$ & $-31.3 \pm 189.9$ \\
\hline \multicolumn{5}{|l|}{ SNP-mediated vasodilation } \\
\hline Baseline flux (PU) & $23.8 \pm 15.8$ & $21.1 \pm 14.1$ & $36.8 \pm 25.9$ & $51.6 \pm 22.9^{* *}$ \\
\hline Change from pretreatment values & & $-3.3 \pm 22.1$ & $12.1 \pm 28.7$ & $22.8 \pm 30.6$ \\
\hline Plateau flux (PU) & $85.2 \pm 60.7$ & $56.4 \pm 70.0$ & $106.3 \pm 102.5$ & $112.1 \pm 48.2$ \\
\hline Change from pretreatment values & & $-29.9 \pm 84.1$ & $13.4 \pm 107.3$ & $29.1 \pm 74.4$ \\
\hline Absolute increase (PU) & $61.4 \pm 52.9$ & $35.3 \pm 61.7$ & $69.5 \pm 86.2$ & $57.5 \pm 64.4$ \\
\hline Change from pretreatment values & & $-25.7 \pm 69.2$ & $1.3 \pm 94.2$ & $-2.6 \pm 84.7$ \\
\hline SNP-mediated vasodilation (\%) & $402.0 \pm 413.0$ & $155.0 \pm 155.4^{* *}$ & $197.8 \pm 171.5$ & $145.7 \pm 130.0$ \\
\hline Change from pretreatment values & & $-244.2 \pm 426.4$ & $-235.3 \pm 436.7$ & $-151.3 \pm 321.2$ \\
\hline
\end{tabular}

Values are expressed as mean \pm standard deviation

$A C h$ acetylcholine, $P U$ arbitrary units of flux, $S N P$ sodium nitroprusside

${ }^{*} p=0.05$ compared to before treatment; ${ }^{* *} p<0.05$ compared to before treatment 
a)

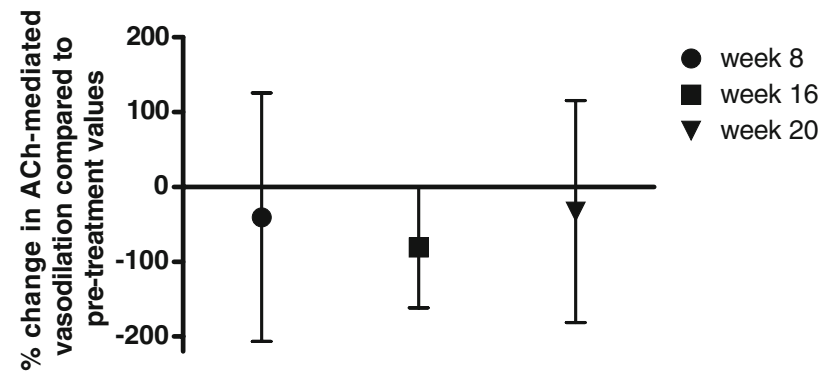

b)

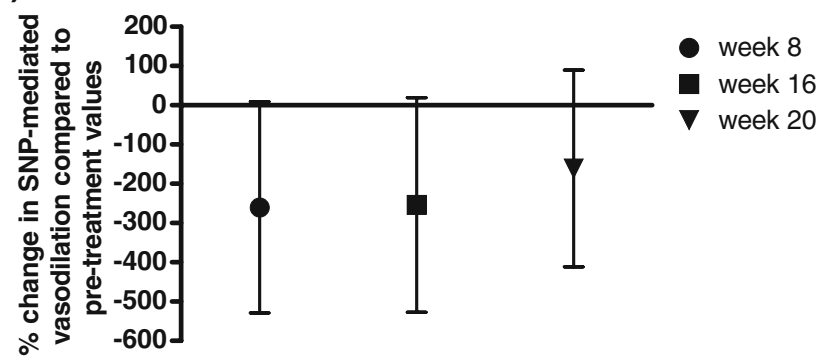

Fig. 1 a Acetylcholine-mediated and b sodium nitroprussidemediated vasodilation during the study period (week 8 and 16 of bosentan treatment) and 4 weeks after discontinuation of bosentan (week 20) compared to pre-treatment vasodilation. Symbols represent the mean; lines represent the $95 \%$ confidence interval

at week 20 suggests a reduced skin blood flow, but no differences were seen in $I_{a v}(7)$ and the curve for relative fluorescence light intensity as compared to baseline.

\section{Nailfold capillary microscopy}

The number of capillaries did not change significantly during the study period. After 16 weeks of treatment, $10.2 \pm$ 6.3 capillaries $/ 3 \mathrm{~mm}$ were seen compared to $9.7 \pm 6.4$ capillaries $/ 3 \mathrm{~mm}$ before treatment with bosentan. Other capillaroscopic features were not noted because of low total number of capillary loops.

Endothelial markers

Concentrations of VCAM- 1 and vWF were not increased in patients with SSc compared to age- and sex-matched healthy controls $(285 \pm 84$ vs $252 \pm 47 \mathrm{ng} / \mathrm{ml}, p=0.171$, and $66 \pm 57$ vs $119 \pm 191 \%, p=0.387$, respectively). Concentrations of TM were increased in patients with $\mathrm{SSc}$ compared to healthy controls $(4.8 \pm 4.2$ vs $3.4 \pm 3.2 \mathrm{ng} / \mathrm{ml}$, $p=0.026$ ). VCAM-1 levels did not change during treatment with bosentan. TM levels significantly decreased after 12 weeks of treatment and remained stably decreased at the end of the study period and after discontinuation of bosentan. vWF was significantly increased at week 4 and 20 compared to pre-treatment values, but was not signifi- cantly different from pre-treatment values at week 8,12 , and 16 (Table 4).

\section{Discussion}

This study is unique in its evaluation of the effects of bosentan on several outcome parameters of microvascular structure and function. Bosentan treatment resulted, in these patients with limited cutaneous SSc and severe RP, as previously shown in our pilot study, in a significant improvement of RP attacks [21]. However, bosentan did not result in any significant changes in microvascular endothelial-dependent and endothelial-independent vasodilation, capillary permeability, and total number of capillary loops. The endothelial marker s-VCAM-1 also remained unchanged, only a decrease in TM was observed during treatment.

The RAPIDS-1 study found significant improvement in the prevention of new digital ulcers only in the SSc patients with a diffuse cutaneous subset [20]. We studied the effects on microvasculature in patients with a limited cutaneous subset, so this might explain why we did not find a positive effect on microvasculature.

Another important finding from this study was the observation that a reduced microvascular vasodilatory response to $\mathrm{ACh}$ was found in our patients, reflecting vasodilatory endothelial dysfunction. The endotheliumindependent vasodilatory response to SNP was comparable to that in healthy controls. This supports not only the presumed microvascular endothelial dysfunction in SSc patients, but also the choice of bosentan as an obvious candidate for the treatment of RP in these patients.

During the last decades, laser Doppler fluxmetry has been used for evaluating skin microcirculation. LDF

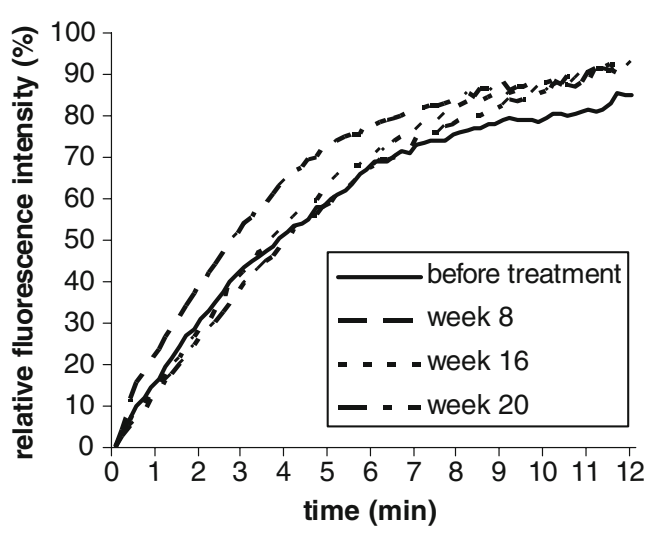

Fig. 2 Relative fluorescence light intensity (\%) after NaF arrival in the skin of patients with systemic sclerosis before treatment, at week 8 and16 of bosentan treatment and at week 20 (4 weeks after discontinuation of bosentan) 
Table 3 Comparison of the NaF leakage curves before treatment, at week 8 and 16 of bosentan treatment, and at week 20 (4 weeks after discontinuation of bosentan)

\begin{tabular}{lllll}
\hline & Before treatment & Week 8 & Week 16 & Week 20 \\
\hline Number & 14 & 14 & 12 & 11 \\
AUC & $2,448 \pm 637$ & $2,918 \pm 611$ & $2,522 \pm 421$ & $2,381 \pm 549$ \\
Dye arrival time (s) & $41 \pm 22$ & $32 \pm 30$ & $45 \pm 23$ & $52 \pm 17^{*}$ \\
$I_{\text {av }}(7)(\%)$ & $43.9 \pm 12.1$ & $46.0 \pm 29.0$ & $44.6 \pm 8.6$ & $41.4 \pm 11.0$ \\
\hline
\end{tabular}

Values are expressed as mean \pm standard deviation

$A U C$ area under the curve, $I_{a v}(7)$ average relative fluorescence light intensity over the first $7 \mathrm{~min}$

${ }^{*} p<0.05$ compared to baseline

provides an estimate of blood flow through the skin [34, 35]. Combining LDF with iontophoresis gives the opportunity to investigate the endothelial-dependent (ACh) and endothelial-independent (SNP) vasodilatory flow responses in the digits or forearm [35]. Impaired microvascular function or endothelium dysfunction, demonstrated as decreased endothelium-dependent microvascular reactivity, has been found in patients with hypertension, diabetes mellitus, obesity, and preeclampsia [24, 26, 28, 29, 36-38]. Reduced endothelium-dependent vasodilatory responses were observed in SSc patients [39, 40]. However, some authors did not find differences in vasodilatory flow responses between patients with $\mathrm{SSc}$, patients with primary $\mathrm{RP}$, and healthy control subjects $[5,41]$. This might be explained by methodological differences, like site differences or a different protocol. In our study we used a protocol with a fair day-to-day reproducibility, expressed as coefficient of variation, of about $10-15 \%$ [26, 28, 29]. Another possible explanation for the lack of improvement in endothelial-dependent vasodilation might be a reduced vasodilatory reserve of the skin microcirculation in patients with SSc, as previously hypothesized [39].

In contrast to our findings, improvement of endothelial function in patients with SSc treated with bosentan was

Table 4 Endothelial markers before treatment, during treatment and after discontinuation of bosentan

\begin{tabular}{lccc}
\hline & s-VCAM-1 (ng/ml) & TM (ng/ml) & vWF (\%) \\
\hline Before treatment & $289 \pm 83$ & $4.8 \pm 4.2$ & $66 \pm 57$ \\
Week 4 & $304 \pm 110$ & $4.5 \pm 2.7$ & $151 \pm 86^{*}$ \\
Week 8 & $292 \pm 94$ & $4.3 \pm 3.2$ & $101 \pm 76$ \\
Week 12 & $291 \pm 94$ & $2.1 \pm 3.3^{*}$ & $96 \pm 103$ \\
Week 16 & $282 \pm 76$ & $2.7 \pm 2.4^{*}$ & $95 \pm 93$ \\
Week 20 & $282 \pm 92$ & $3.2 \pm 3.7^{*}$ & $147 \pm 78^{*, * *}$ \\
\hline
\end{tabular}

Values are expressed as mean \pm standard deviation

$s$-VCAM-1 serum vascular cellular adhesion molecule-1, TM thrombomodulin, $v W F$ von Willebrand factor

${ }^{*} p<0.05$ compared to baseline; ${ }^{* *} p<0.05$ compared to week 16 found by Sfikakis et al. [42] as shown by a significant increase in brachial artery ultrasound-derived flowmediated dilation (FMD) following bosentan treatment. The discrepancy in the treatment effect of bosentan on endothelial dysfunction might be explained by differences in vascular bed and in technique used. To study endothelial function in conduit arteries, ultrasound has been used to measure FMD of the brachial artery, while LDF is used for measurement of flow in the microcirculation. Comparison between these two different non-invasive methods has revealed conflicting results [43, 44]. However, our study does also confirms the results found by Sfikakis et al. [42] since no positive effect of bosentan on peripheral flow reserve and forearm blood flow using venous occlusion plethysmography was observed in this study, probably due to irreversible structural changes since most patients had a well-established disease. We cannot rule out irreversible structural vascular abnormalities in our patients, prohibiting vascular remodeling. Focal stenosis and occlusion in digital arteries, e.g. the proper digital arteries and ulnar artery, are common manifestations in SSc patients [45, 46]. Our results are consistent with a previous report, in which treatment of bosentan during 24 weeks did not reveal a significant improvement in endothelial-dependent and endothelial-independent vasodilation of the digits [47].

In patients with $\mathrm{SSc}$, transcapillary leakage of $\mathrm{NaF}$ has usually been determined at the nailfold capillaries. A major limitation of this technique in intervention studies has been the large variability in leakage between visualized capillaries. In previous studies we adapted this technique using large-window videodensitometry with sodium fluorescein $(\mathrm{NaF})$ of the forefoot [48] or medial ankle [30, 49] to reduce this variability and make it a suitable tool for intervention studies. Using this technique, our study showed no improvement during bosentan treatment in total number of capillaries and in transcapillary leakage. A trend to increased $\mathrm{NaF}$ leakage was seen after 8 weeks of treatment together with a non-significant decrease in dye arrival time, suggesting bosentan-related increase in total skin blood flow. However, no differences in NaF leakage 
parameters were present after 16 weeks of treatment. Such relatively minor changes in permeability, and the increased DAT at week 20, suggest that these changes are caused by a decrease in blood flow, since DAT is mainly determined by skin blood flow. A difference in temperature cannot be held responsible since room temperature and local skin temperature remained stable.

In our study, endothelial activation markers did not show consistent changes during treatment with bosentan. We did find a significant decrease in TM from week 12 till the end of the study. This result suggests improvement of endothelial dysfunction, i.e. decrease in endothelial cell damage, especially since baseline values were increased compared to healthy controls. Otherwise, we did not find a difference in levels of s-VCAM and vWF between SSc patients and healthy controls. Soluble adhesion molecules, like s-VCAM-1 are increased particularly during the early edematous phase of the disease [11]. The fact that none of our patients had early or active disease might explain lack of differences, but is also consistent with a previous report in which bosentan did not result in changes of ET-1, soluble intercellular adhesion molecule 1 (ICAM-1) and E-selectin [42]. The observed increase of vWF at week 4 and 20 could be related to cold exposition shortly before $[50,51]$ as some patients had been exposed to cold more than $30 \mathrm{~min}$ prior to blood collection, though skin temperature had returned to normal at this time point. Levels of s-VCAM and TM were not supposed to be influenced by cold exposition [51,52].

Obviously, the major limitation of our study is its uncontrolled and open design and its relatively short duration. Also, patients were allowed to continue other vasodilating agents besides prostanoids. Therefore, a possible effect of bosentan on vasodilating responses and capillary permeability might be reduced. On the other hand, we found no positive effect of bosentan on microvascular structure and function. Since placebo is not supposed to be an effective therapy, the chance to find a beneficial effect of bosentan in a placebocontrolled trial in a short-time study is not to be expected. One might argue that seasonal variation could have influenced the results of the vascular studies. Although we cannot completely rule out a seasonal effect, outdoor temperature remained stable in all patients until week 12 .

In conclusion, the findings of this observational study indicate that use of the endothelin-1 receptor antagonist does not induce changes in vasodilator responses, capillary permeability, and capillary density during a period of 16 weeks treatment in patients with lcSSc. As we found a decrease in TM, some limited improvement of endothelial cell dysfunction cannot be ruled out. A prospective controlled study, possibly with a longer follow-up is warranted in order to examine the efficacy of bosentan on functional and structural abnormalities in the microvasculature in patients with early $\mathrm{SSc}$ with raised endothelial activation markers.
Acknowledgements This study was supported by an unrestricted grant from Actelion, The Netherlands

Disclosures None.

Open Access This article is distributed under the terms of the Creative Commons Attribution Noncommercial License which permits any noncommercial use, distribution, and reproduction in any medium, provided the original author(s) and source are credited.

\section{References}

1. Leroy EC, Black C, Fleischmajer R, Jablonska S, Krieg T, Medsger TA et al (1988) Scleroderma (systemic-sclerosis)classification, subsets and pathogenesis. J Rheumatol 15:202-205

2. Wigley FM (2002) Clinical practice. Raynaud's phenomenon. N Engl J Med 347:1001-1008

3. Bollinger A, Jager K, Siegenthaler W (1986) Microangiopathy of progressive systemic sclerosis. Evaluation by dynamic fluorescence videomicroscopy. Arch Intern Med 146:1541-1545

4. Grassi W, Core P, Carlino G, Cervini C (1994) Effects of peripheral cold exposure on microvascular dynamics in systemic sclerosis. Arthritis Rheum 37:384-390

5. Anderson ME, Campbell F, Hollis S, Moore T, Jayson MI, Herrick AL (1999) Non-invasive assessment of digital vascular reactivity in patients with primary Raynaud's phenonenon and systemic sclerosis. Clin Exp Rheumatol 17:49-54

6. Generini S, Kahaleh B, Matucci-Cerinic M, Pignone A, Lombardi A, Ohtsuka T (1996) Raynaud's phenomenon and systemic sclerosis. Ann Ital Med Int 11:125-131

7. Kahaleh B, Matucci-Cerinic M (1995) Raynaud's phenomenon and scleroderma. Dysregulated neuroendothelial control of vascular tone. Arthritis Rheum 38:1-4

8. Andersen GN, Caidahl K, Kazzam E, Petersson AS, Waldenstrom A, Mincheva-Nilsson L et al (2000) Correlation between increased nitric oxide production and markers of endothelial activation in systemic sclerosis: findings with the soluble adhesion molecules E-selectin, intercellular adhesion molecule 1, and vascular cell adhesion molecule 1. Arthritis Rheum 43:1085-1093

9. Cerinic MM, Valentini G, Sorano GG, D'Angelo S, Cuomo G, Fenu L et al (2003) Blood coagulation, fibrinolysis, and markers of endothelial dysfunction in systemic sclerosis. Semin Arthritis Rheum 32:285-295

10. Denton CP, Bickerstaff MC, Shiwen X, Carulli MT, Haskard DO, Dubois RM et al (1995) Serial circulating adhesion molecule levels reflect disease severity in systemic sclerosis. $\mathrm{Br} \mathrm{J}$ Rheumatol 34:1048-1054

11. Gruschwitz MS, Hornstein OP, von Den DP (1995) Correlation of soluble adhesion molecules in the peripheral blood of scleroderma patients with their in situ expression and with disease activity. Arthritis Rheum 38:184-189

12. Herrick AL, Illingworth K, Blann A, Hay CR, Hollis S, Jayson MI (1996) Von Willebrand factor, thrombomodulin, thromboxane, beta-thromboglobulin and markers of fibrinolysis in primary Raynaud's phenomenon and systemic sclerosis. Ann Rheum Dis 55:122-127

13. Ihn H, Sato S, Fujimoto M, Takehara K, Tamaki K (1998) Increased serum levels of soluble vascular cell adhesion molecule-1 and E-selectin in patients with systemic sclerosis. Br J Rheumatol 37:1188-1192

14. Ferri C, Latorraca A, Catapano G, Greco F, Mazzoni A, Clerico A et al (1993) Increased plasma endothelin-1 immunoreactive levels 
in vasculitis: a clue to the use of endothelin-1 as a marker of vascular damage? J Hypertens Suppl 11(Suppl 5):S142-S143

15. Filep JG, Bodolay E, Sipka S, Gyimesi E, Csipo I, Szegedi G (1995) Plasma endothelin correlates with antiendothelial antibodies in patients with mixed connective-tissue disease. Circulation 92:2969-2974

16. Julkunen H, Saijonmaa O, Gronhagen-Riska C, Teppo AM, Fyhrquist F (1991) Raised plasma concentrations of endothelin-1 in systemic lupus erythematosus. Ann Rheum Dis 50:526-527

17. Kahaleh MB (1991) Endothelin, an endothelial-dependent vasoconstrictor in scleroderma - enhanced production and profibrotic action. Arthritis Rheum 34:978-983

18. Morelli S, Ferri C, Polettini E, Bellini C, Gualdi GF, Pittoni V et al (1995) Plasma endothelin-1 levels, pulmonary-hypertension, and lung fibrosis in patients with systemic-sclerosis. Am J Med 99:255-260

19. Yamane K, Kashiwagi H, Suzuki N, Miyauchi T, Yanagisawa M, Goto K et al (1991) Elevated plasma-levels of endothelin-1 in systemic-sclerosis. Arthritis Rheum 34:243-244

20. Korn JH, Mayes M, Matucci Cerinic M, Rainisio M, Pope J, Hachulla E et al (2004) Digital ulcers in systemic sclerosis: prevention by treatment with bosentan, an oral endothelin receptor antagonist. Arthritis Rheum 50:3985-3993

21. Hettema ME, Zhang D, Bootsma H, Kallenberg CGM (2007) Bosentan therapy for patients with severe Raynaud's phenomenon in systemic sclerosis. Ann Rheum Dis 66:1398-1399

22. Wouda AA (1977) Raynaud's phenomenon. Photoelectric plethysmography of the fingers of persons with and without Raynaud's phenomenon during cooling and warming up. Acta Med Scand 201:519-523

23. Subcommittee for Scleroderma Criteria of the American Rheumatism Association Diagnostic and Therapeutic Criteria Committee (1980) Preliminary criteria for the classification of systemicsclerosis (scleroderma). Arthritis Rheum 23:581-590

24. Blaauw J, Graaff R, van Pampus MG, van Doormaal JJ, Smit AJ, Rakhorst $G$ et al (2005) Abnormal endothelium-dependent microvascular reactivity in recently preeclamptic women. Obstet Gynecol 105:626-632

25. Cracowski JL, Carpentier PH, Imbert B, Cachot S, Stanke-Labesque F, Bessard J et al (2002) Increased urinary F2-isoprostanes in systemic sclerosis, but not in primary Raynaud's phenomenon: effect of cold exposure. Arthritis Rheum 46:1319-1323

26. Serne EH, Gans ROB, ter Maaten JC, ter Wee PM, Donker AM, Stehouwer CDA (2001) Capillary recruitment is impaired in essential hypertension and relates to insulin's metabolic and vascular actions. Cardiovasc Res 49:161-168

27. Morris SJ, Shore AC, Tooke JE (1995) Responses of the skin microcirculation to acetylcholine and sodium nitroprusside in patients with NIDDM. Diabetologia 38:1337-1344

28. de Jongh RT, Serne EH, Ijzerman RG, de Vries G, Stehouwer CD (2004) Impaired microvascular function in obesity: implications for obesity-associated microangiopathy, hypertension, and insulin resistance. Circulation 109:2529-2535

29. Serne EH, Stehouwer CD, ter Maaten JC, ter Wee PM, Rauwerda JA, Donker AJ et al (1999) Microvascular function relates to insulin sensitivity and blood pressure in normal subjects. Circulation 99:896-902

30. Jager J, Oomen PH, Sluiter WJ, Reitsma WD, Smit AJ (1997) Improved reproducibility of the 'large-window' method of assessing transcapillary and interstitial fluorescein diffusion in the skin in healthy subjects and in subjects with insulin-dependent diabetes mellitus. Int J Microcirc Clin Exp 17:150-158

31. Oomen PH, Jager J, Hoogenberg K, Dullaart RP, Reitsma WD, Smit AJ (1999) Capillary permeability is increased in normo- and microalbuminuric type 1 diabetic patients: amelioration by ACEinhibition. Eur J Clin Invest 29:1035-1040
32. Houtman PM. Microvascular and immunological studies in Raynaud's phenomenon. Academic thesis Groningen, the Netherlands 1985

33. De Leeuw K, Sanders JS, Stegeman C, Smit A, Kallenberg CG, Bijl M (2005) Accelerated atherosclerosis in patients with Wegener's granulomatosis. Ann Rheum Dis 64:753-759

34. Fagrell B (1995) Advances in microcirculation network evaluation: an update. Int J Microcirc Clin Exp 15(Suppl 1):34-40

35. Wright CI, Kroner CI, Draijer R (2006) Non-invasive methods and stimuli for evaluating the skin's microcirculation. J Pharmacol Toxicol Methods 54:1-25

36. Farkas K, Kolossvary E, Jarai Z, Nemcsik J, Farsang C (2004) Non-invasive assessment of microvascular endothelial function by laser Doppler flowmetry in patients with essential hypertension. Atherosclerosis 173:97-102

37. Ijzerman RG, de Jongh RT, Beijk MA, van Weissenbruch MM, Delemarre-van de Waal HA, Serne EH et al (2003) Individuals at increased coronary heart disease risk are characterized by an impaired microvascular function in skin. Eur J Clin Invest 33:536-542

38. Khan F, Elhadd TA, Greene SA, Belch JJ (2000) Impaired skin microvascular function in children, adolescents, and young adults with type 1 diabetes. Diabetes Care 23:215-220

39. La Civita L, Rossi M, Vagheggini G, Storino FA, Credidio L, Pasero G et al (1998) Microvascular involvement in systemic sclerosis: laser Doppler evaluation of reactivity to acetylcholine and sodium nitroprusside by iontophoresis. Ann Rheum Dis 57:52-55

40. Marasini B, Conciato L (2001) Iontophoretic evaluation of vascular reactivity to acetylcholine in patients with primary Raynaud's phenomenon and systemic sclerosis. Clin Rheumatol 20:451-452

41. Anderson ME, Hollis S, Moore T, Jayson MI, Herrick AL (1996) Non-invasive assessment of vascular reactivity in forearm skin of patients with primary Raynaud's phenomenon and systemic sclerosis. Br J Rheumatol 35:1281-1288

42. Sfikakis PP, Papamichael C, Stamatelopoulos KS, Tousoulis D, Fragiadaki KG, Katsichti $P$ et al (2007) Improvement of vascular endothelial function using the oral endothelin receptor antagonist bosentan in patients with systemic sclerosis. Arthritis Rheum 56:1985-1993

43. Gori T, Di SG, Sicuro S, Dragoni S, Lisi M, Parker JD et al (2006) Correlation analysis between different parameters of conduit artery and microvascular vasodilation. Clin Hemorheol Microcirc 35:509-515

44. Hansell J, Henareh L, Agewall S, Norman M (2004) Non-invasive assessment of endothelial function - relation between vasodilatory responses in skin microcirculation and brachial artery. Clin Physiol Funct Imaging 24:317-322

45. Dick EA, Aviv R, Francis I, Hamilton G, Baker D, Black C et al (2001) Catheter angiography and angioplasty in patients with scleroderma. Br J Radiol 74:1091-1096

46. Stucker M, Quinna S, Memmel U, Rochling A, Traupe M, Hoffmann K et al (2000) Macroangiopathy of the upper extremities in progressive systemic sclerosis. Eur J Med Res 5:295-302

47. Moore TL, Vail A, Herrick AL (2007) Assessment of digital vascular structure and function in response to bosentan in patients with systemic sclerosis-related Raynaud's phenomenon. Rheumatology (Oxford) 46:363-364

48. Baer-Suryadinata C, Bollinger A (1985) Transcapillary diffusion of Na-fluorescein measured by a 'large window technique' in skin areas of the forefoot. Int J Microcirc Clin Exp 4:217-228

49. Oomen PH, Kant GD, Dullaart RP, Tervaert JW, Reitsma WD, Smit AJ (2004) No effects of acute hyperglycaemia and hyperinsulinaemia on skin microcirculation and endothelial markers in Type II diabetes mellitus. Scand J Clin Lab Invest 64:119-127

50. Kahaleh MB, Osborn I, Leroy EC (1981) Increased factor VIII/ von Willebrand factor antigen and von Willebrand factor activity 
in scleroderma and in Raynaud's phenomenon. Ann Intern Med 94:482-484

51. Matsuda J, Tsukamoto M, Gohchi K, Saitoh N, Miyajima Y, Kazama M (1992) Effect of total-body cold exposure on plasma concentrations of von Willebrand factor, endothelin-1 and thrombomodulin in systemic lupus erythematosus patients with or without Raynaud's phenomenon. Acta Haematol 88:189-193

52. Brevetti G, De Caterina M, Martone VD, Corrado S, Silvestro A, Spadaro G et al (2000) Measurement of soluble adhesion molecules in primary Raynaud's phenomenon and in Raynaud's phenomenon secondary to connective tissue diseases. Int J Clin Lab Res 30:75-81 